\title{
Evaluasi Pengendalian Aplikasi Pada Sistem Informasi Manajemen Keuangan Menggunakan Framework COSO
}

\author{
Agus Eko Musantono ${ }^{1)}$, Bambang Soedijono W.A ${ }^{2)}$, Asro Nasiri ${ }^{3)}$ \\ ${ }^{1,2,3)}$ Magister Teknologi Informasi Universitas AMIKOM Yogyakarta \\ Jalan Ring Road Utara, Condongcatur, Sleman, Yogyakarta 55281 \\ 1agus.0943@students.amikom.ac.id, ${ }^{2}$ bambang.s@amikom.ac.id, ${ }^{3}$ asro@amikom.ac.id
}

\begin{abstract}
Abstrak
Pengendalian aplikasi merupakan suatu pengendalian internal komputer yang berlaku khusus untuk aplikasi komputerisasi atau sistem informasi pada suatu organisasi sehingga sebaiknya perlu dilakukan evaluasi pengendalian aplikasi pada sistem informasi untuk menghindari atau meminimalisir dari kesalahan sistem informasi yang dapat merugikan organisasi. Sistem Informasi Manajemen Keuangan merupakan suatu implementasi TI yang dapat memberikan manfaat juga dapat menimbulkan risiko yang dapat merugikan dan mempengaruhi proses bisnis atau pekerjaan. Evaluasi pengendalian aplikasi Sistem Informasi Manajemen Keuangan pemerintah kabupaten Banyuwangi perlu dilakukan untuk mengurangi terjadinya risiko, penyalahgunaan terhadap kecurangan serta meningkatkan kinerja suatu aplikasi dan apabila risiko tersebut terjadi sebaiknya tingkat kerugiannya agar seminimal mungkin. Pendekatan yang dilakukan yaitu menggunakan metode audit through computer yaitu pelaksanaan tahapan input, process dan output dilakukan secara langsung pada aplikasi atau sistem informasi. Hasil evaluasi pengendalian aplikasi dari sistem informasi manajemen keuangan kabupaten Banyuwangi didapatkan nilai 84,5 dengan kriteria penilaian baik. Pengendalian aplikasi dapat digunakan untuk memperbaiki kelemahan sistem informasi yang telah dikembangkan, menjaga keamanan data dan informasi, meminimal risiko sistem informasi yang dapat merugikan pihak terkait serta menjaga keberlangsungan sistem informasi.
\end{abstract}

Kata kunci:evaluasi pengendalian aplikasi, pengendalian aplikasi COSO, audit sistem informasi.

\section{PENDAhuluan}

Pemanfaatan Teknologi Informasi saat ini telah berkembang pada sektor pemerintahan salah satunya adalah sistem informasi manajemen keuangan pemerintah kabupaten Banyuwangi. Sistem informasi manajemen keuangan ini digunakan untuk mengelola keuangan pemerintahan kabupaten Banyuwangi yang dikembangkan oleh Kementrian Komunikasi dan Informatika Republik Indonesia (Kemkominfo RI) Banyuwangi. Kemkominfo adalah suatu badan kementrian Republik Indonesia yang membidangi tentang komunikasi dan informatika yang dipimpin oleh Menteri Komunikasi dan Informatika (Hidayat, 2017). Sistem Informasi Manajemen Keuangan merupakan suatu implementasi TI namun implementasi TI dalam suatu badan pemerintahan selain dapat memberikan manfaat juga dapat menimbulkan risiko yang dapat merugikan dan mempengaruhi proses bisnis atau pekerjaan. Kegagalan atau kesalahan dalam pengembangan proyek sistem informasi juga dapat dikategorikan sebagai risiko sistem informasi yang harus diantisipasi. Jika risiko-risiko tersebut tidak dikelola dengan baik maka akan menimbulkan dampak yang merugikan bagi badan pemerintahan dalam mencapai tujuannya (Paulina, 2014), sehingga perlu dilakukan evaluasi pengendalian internal untuk menangani permasalahan tersebut (Fajar, 2018).

COSO merupakan salah satu framework yang digunakan sebagai referensi untuk pengendalian internal. Pada model COSO terdapat dua jenis aktivitas pengendalian internal yaitu pengendalian umum dan pengendalian aplikasi. Pengendalian aplikasi merupakan suatu pengendalian internal komputer yang berlaku khusus untuk aplikasi komputerisasi atau sistem informasi pada suatu organisasi (Gondodiyoto, 2007) sehingga sebaiknya perlu dilakukan evaluasi pengendalian 
aplikasi pada sistem informasi untuk menghindari atau meminimalisir dari kesalahan sistem informasi yang dapat merugikan organisasi.

Evaluasi pengendalian aplikasi Sistem Informasi Manajemen Keuangan pemerintah kabupaten Banyuwangi perlu dilakukan untuk mengurangi terjadinya risiko, penyalahgunaan terhadap kecurangan serta meningkatkan kinerja suatu aplikasi dan apabila risiko tersebut terjadi sebaiknya tingkat kerugiannya agar seminimal mungkin (Manurung, 2014). Dengan merancang uji pengendalian secara detail akan membuat organisasi mendapatkan informasi tentang kelebihan dan kekurangan aplikasinya (Papilaya, 2017).

Penelitian Papilaya, dkk (2017) melakukan evaluasi pengendalian aplikasi pada sistem informasi keuangan dan akuntansi satya wacana menyimpulkan bahwa evaluasi pengendalian aplikasi dirasa perlu untuk mengetahui keandalan sistem dan meminimalisir risiko yang ada, sehingga pemberian rekomendasi pengendalian sangat diperlukan untuk meminimalisir dampak risiko maupun frekuensi terjadinya dikemudian hari.

Hasil akhir pada penelitian ini adalah mengevaluasi sistem informasi manajemen keuangan yang digunakan pemerintah Banyuwangi berupa uji pengendalian aplikasi, mengetahui hasil temuan pengendalian aplikasi, memeberikan penilaian hasil evaluasi serta memberikan rekomendasi pengendalian aplikasi dari hasil evaluasi atau hasil temuan.

\section{METODE PENELITIAN}

Metode penelitian yang digunakan yaitu metode kualitatif dengan pendekatan studi kasus. Studi kasus penelitian ini adalah terhadap sistem informasi manajemen keuangan pada dinas komunikasi informatika dan persandian kabupaten Banyuwangi .Proses pengumpulan data pada penelitian ini dilakukan dengan cara wawancara dan observasi. Tahap awal yaitu dengan melakukan evaluasi terhadap aplikasi sistem informasi kemudian dikelola risikonya. Setelah diketahui hasil temuan risikonya. Pendekatan yang dilakukan yaitu menggunakan metode audit through computer yaitu pelaksanaan tahapan input, process dan output dilakukan secara langsung pada aplikasi atau sistem informasi.
Metode dalam pengumpulan data dilakukan dengan cara melakukan penggalian informasi dari pihak-pihak yang terlibat dalam sistem informasi tersebut, penggalian informasi dilakukan dengan wawancara yang mendalam dan observasi. Observasi dilakukan dengan pengujian langsung terhadap sistem informasi manajemen keuangan yang sedang berjalan pada saat itu sesuai pengendalian yang telah ditentukan oleh peneliti.

Setelah semua data terkumpul dengan lengkap, selanjutnya data diolah dan dianalisis secara kualitatif dengan memperhatikan faktafakta yang terjadi dilapangan berdasarkan variabel yang sudah ditentukan, kemudian dimasukkan kedalam tahapan analisis. Analisis dilakukan untuk mendapatkan hasil nilai dan rekomendasi dari penelitian. 
Adapun alur pada penelitian ini adalah:

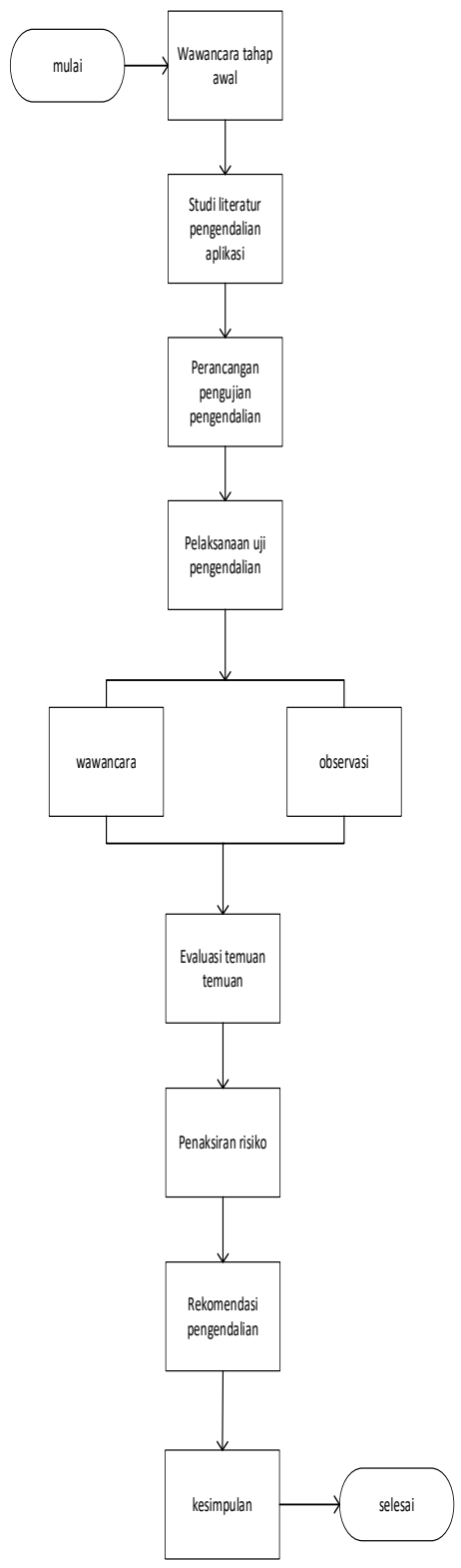

Gambar 1. Alur Penelitian

Adapun ruang lingkup pada kegiatan pengendalian aplikasi yang adalah:

Tabel 1. Ruang Lingkup

Pengendalian Aplikasi

\begin{tabular}{|l|l|}
\hline $\begin{array}{l}\text { Kategori } \\
\text { Pengendalian }\end{array}$ & $\begin{array}{l}\text { Jenis-jenis } \\
\text { Pengendalian }\end{array}$ \\
\hline 1. $\begin{array}{l}\text { Boundary } \\
\begin{array}{l}\text { Control } \\
\text { (Pengendalian } \\
\text { Batasan) }\end{array}\end{array}$ & $\bullet \begin{array}{l}\text { Otoritas akses ke } \\
\text { sistem aplikasi } \\
\text { Identitas dan } \\
\text { otentisitas } \\
\text { pengguna }\end{array}$ \\
\hline
\end{tabular}

\begin{tabular}{|c|c|}
\hline $\begin{array}{l}\text { Kategori } \\
\text { Pengendalian }\end{array}$ & $\begin{array}{l}\text { Jenis-jenis } \\
\text { Pengendalian } \\
\end{array}$ \\
\hline $\begin{array}{l}\text { 2. Input Control } \\
\text { (Pengendalian } \\
\text { Masukan) }\end{array}$ & $\begin{array}{ll}\text { - } & \text { Otorisasi dan } \\
& \text { validasi masukan } \\
\text { - } & \text { Transmisi dan } \\
\text { konversi data } \\
\text { - } \begin{array}{l}\text { Penanganan } \\
\text { kesalahan }\end{array} \\
\end{array}$ \\
\hline 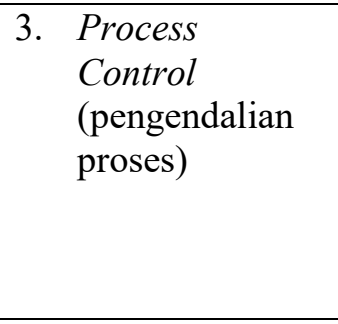 & $\begin{array}{ll}\text { - } & \text { Pemeliharaan } \\
\text { ketepatan data } \\
\text { - Pengujian } \\
\text { terprogram atas } \\
\text { batasan dan } \\
\text { memadainya } \\
\text { pengolahan } \\
\end{array}$ \\
\hline $\begin{array}{l}\text { 4. Output Control } \\
\text { (Pengendalian } \\
\text { Keluaran) }\end{array}$ & 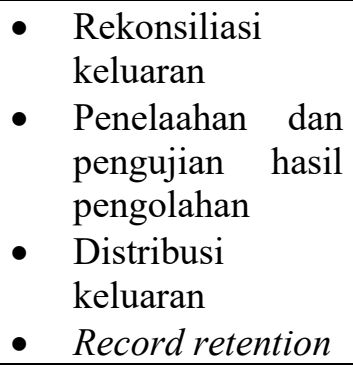 \\
\hline 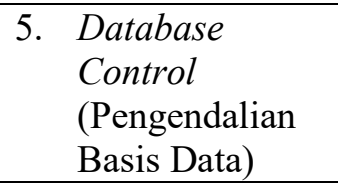 & $\begin{array}{ll}\text { - } & \text { Akses } \\
\text { - } & \text { Integritas data }\end{array}$ \\
\hline $\begin{array}{l}\text { 6. } \text { Communication } \\
\text { Control } \\
\text { (Pengendalian } \\
\text { Komunikasi } \\
\text { Aplikasi) }\end{array}$ & 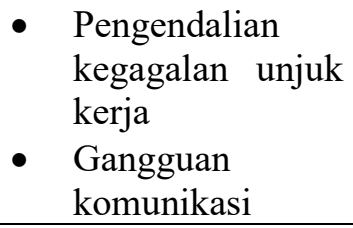 \\
\hline
\end{tabular}

\section{TINJAUAN PUSTAKA}

a. Pengendalian Aplikasi

Pengendalian khusus atau pengendalian aplikasi (application controls) adalah kontrol internal komputer yang berlaku khusus untuk aplikasi komputerisasi tertentu pada suatu organisasi (Gondodiyoto, 2007). Pengendalian aplikasi sering disebut pengendalian perspektif teknis atau dapat didefinisikan sebagai pengendalian yang langsung terkait dengan transaksi pada suatu aplikasi tertentu. Pada dasarnya pengendalian aplikasi terdiri dari pengendalian masukan (input control), pengendalian proses (process control), dan pengendalian keluaran (output control). Beberapa text-book menyebutkan juga tentang pengendalian database (database control), pengendalian komunikasi (communication control), dan boundary control (Rivai, 2012). 


\section{b. COSO}

Internal Control $\quad-$ Integrated Framework yang dikeluarkan oleh Committee of Sponsoring Organizations of the Treadway Commission (COSO), yaitu kerangka kerja pengendalian internal yang dirancang dan diimplementasikan untuk manajemen dalam memberikan kepastian yang layak bahwa tujuan pengendaliannya akan tercapai (Aviana \& Mega, 2012).

Jenis-jenis pengendalian yang digunakan oleh perusahaan untuk menjamin integritas sistem informasi akuntansi (Krismiaji, 2002):

1. Pengendalian umum

Pengendalian umum dirancang untuk menjamin bahwa seluruh sistem komputer dapat berfungsi secara optimal dan pengolahan data dapat dilakukan secara lancar sesuai dengan yang direncanakan. Pengendalian umum dapat dilakukan dengan cara sebagai berikut:

a) Penyusunan rencana pengamanan

b) Pemisahan tugas dalam fungsi sistem informasi

c) Pengendalian proyek penyusunan sistem informasi

d) Pengendalian akses fisik

e) Pengendalian akses login

f) Pengendalian penyimpanan data

g) Pengendalian transmisi data

h) Standar dokumentasi

i) Meminimumkan penghentian sistem informasi

j) Rencana pemulihan kerusakan

k) Perlindungan terhadap komputer dan jaringan

1) Pengendalian internet

\section{Pengendalian aplikasi}

Tujuan utama pengendalian aplikasi adalah untuk menjamin akurasi dan validitas input, proses, dan output program aplikasi. Pengendalian aplikasi dan pengendalian umum saling melengkapi satu sama lain, jadi keduanya penting dan perlu, karena pengendalian aplikasi jauh lebih efektif jika didukung oleh adanya pengendalian umum yang kuat. Jika pengendalian aplikasi lemah, maka output sistem informasi akan mengandung kesalahan. Mengandung kesalahan ini jika digunakan untuk membuat keputusan, akan menghasilkan keputusan yang tidak tepat atau keliru, dan dapat berpengaruh terhadap hubungan antara perusahaan dengan pelanggan, pemasok, dan pihak eksternal lainnya.

\section{HASIL DAN PEMBAHASAN}

Berdasarkan hasil wawancara dan observasi dari pengendalian aplikasi yang telah dilakukan didapatkan hasil kriteria penilaian dan rekomendasi hasil temuan dari risiko masing-masing pengujian pengendalian. Adapun penentuan kriteria penilaian adalah sebagai berikut:

Tabel 2. Kriteria Penilaian

\begin{tabular}{|c|c|}
\hline Nilai & Kriteria \\
\hline $67-100$ & Baik \\
\hline $34-66$ & Cukup \\
\hline $0-33$ & Kurang \\
\hline
\end{tabular}

Perhitungan nilai dari tiap kategori pengendalian adalah:

$$
\frac{\sum \text { temuan positif }}{\sum \text { pengujian }-(N / A)} \times 100 \%
$$

Keterangan:

$\sum=$ total dari

$\mathrm{N} / \mathrm{A}=$ not applicable

Penilaian dari pengendalian aplikasi pada masing-masing kategori pengendalian telah didapatkan hasilnya yaitu:

Tabel 3. Hasil Penilaian Pengendalian Aplikasi

\begin{tabular}{|l|l|l|l|l|}
\hline $\begin{array}{l}\text { Kategori } \\
\text { Pengendalian }\end{array}$ & $\begin{array}{l}\text { Jumlah } \\
\text { Pengujian }\end{array}$ & $\begin{array}{l}\text { Temuan } \\
\text { Positif }\end{array}$ & Nilai & $\begin{array}{l}\text { Kriter } \\
\text { ia }\end{array}$ \\
\hline $\begin{array}{l}\text { Pengendalian } \\
\text { batasan }\end{array}$ & 14 & 11 & 78 & Baik \\
\hline $\begin{array}{l}\text { Pengendalian } \\
\text { masukan }\end{array}$ & 25 & 21 & 84 & Baik \\
\hline $\begin{array}{l}\text { Pengendalian } \\
\text { proses }\end{array}$ & 7 & 7 & 100 & Baik \\
\hline $\begin{array}{l}\text { Pengendalian } \\
\text { keluaran }\end{array}$ & 12 & 11 & 91 & Baik \\
\hline $\begin{array}{l}\text { Pengendalian } \\
\text { basis data }\end{array}$ & 9 & 8 & 88 & Baik \\
\hline $\begin{array}{l}\text { Pengendalian } \\
\text { komunikasi } \\
\text { aplikasi }\end{array}$ & 9 & 6 & 66 & Cukup \\
\hline $\begin{array}{l}\text { Rata-rata } \\
\text { and }\end{array}$ & & $\mathbf{8 4 . 5}$ & Baik \\
\hline
\end{tabular}


Selanjutnya adalah pemberian rekomendasi dari temuan risiko pada masingmasing kategori pengendalian:

Tabel 4. Rekomendasi Temuan Risiko

\begin{tabular}{|c|c|c|}
\hline $\begin{array}{l}\text { Kategori } \\
\text { Pengendali } \\
\text { an }\end{array}$ & Risiko & Rekomendasi \\
\hline \multirow[t]{2}{*}{$\begin{array}{l}\text { Pengendalia } \\
\mathrm{n} \text { batasan }\end{array}$} & $\begin{array}{l}\text { Tidak adanya } \\
\text { batasan pada } \\
\text { respon } \\
\text { kegagalan login, } \\
\text { hal ini akan } \\
\text { memberi } \\
\text { kemudahan pada } \\
\text { orang yang tidak } \\
\text { memiliki otoritas } \\
\text { untuk mencoba } \\
\text { masuk ke sistem } \\
\text { dengan } \\
\text { memanfaatkan } \\
\text { celah tersebut }\end{array}$ & 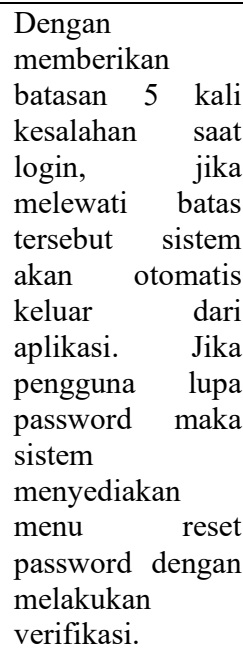 \\
\hline & $\begin{array}{l}\text { Tidak adanya } \\
\text { pemberitahuan } \\
\text { saat password } \\
\text { telah expired, hal } \\
\text { ini dapat } \\
\text { membingungkan } \\
\text { user saat hendak } \\
\text { login } \\
\text { dikarenakan } \\
\text { permintaan } \\
\text { sistem yang } \\
\text { tidak jelas }\end{array}$ & \begin{tabular}{lr}
\multicolumn{2}{l}{ Menambahkan } \\
peringatan saat \\
password telah \\
expired sehingga \\
user r bisa \\
mengetahui \\
dengan jelas \\
permintaan \\
sistem.
\end{tabular} \\
\hline $\begin{array}{l}\text { Pengendalia } \\
\text { n masukan }\end{array}$ & $\begin{array}{l}\text { Tidak adanya } \\
\text { perubahan warna } \\
\text { pada interface } \\
\text { saat terjadi } \\
\text { kesalahan input, } \\
\text { sehingga user } \\
\text { tidak mudah } \\
\text { mengenali jenis } \\
\text { peringatan saat } \\
\text { sistem tem kesalahan } \\
\text { terjadi } \\
\text { input }\end{array}$ & $\begin{array}{l}\text { Dengan } \\
\text { menambahkan } \\
\text { perubahan warna } \\
\text { pada } \\
\text { pemberitahuan } \\
\text { sehingga user } \\
\text { mudah mengenali } \\
\text { jenis } \\
\text { pemberitahuan } \\
\text { berdasarkan dari } \\
\text { warnanya }\end{array}$ \\
\hline $\begin{array}{l}\text { Pengendalia } \\
\mathrm{n} \text { proses }\end{array}$ & $\begin{array}{l}\text { Tidak ditemukan } \\
\text { risiko pada } \\
\text { pengendalian } \\
\text { proses }\end{array}$ & $\begin{array}{l}\text { Pengendalian } \\
\text { proses sudah } \\
\text { mencapai target }\end{array}$ \\
\hline $\begin{array}{l}\text { Pengendalia } \\
\text { n keluaran }\end{array}$ & $\begin{array}{l}\text { Tidak ada } \\
\text { penghancuran } \\
\text { laporan yang } \\
\text { sudah tidak } \\
\text { digunakan lagi } \\
\text { dan batas waktu } \\
\text { pengarsipan } \\
\text { laporan, hal ini } \\
\text { dapat } \\
\text { mempengaruhi } \\
\text { penuhnya } \\
\text { memori }\end{array}$ & $\begin{array}{l}\text { Dengan } \\
\text { menetapkan batas } \\
\text { waktu umur } \\
\text { pengarsipan } \\
\text { laporan } 10 \text { tahun } \\
\text { dan } \\
\text { menghancurkan } \\
\text { laporan yang } \\
\text { sudah tidak } \\
\text { digunakan agar } \\
\text { tidak memenuhi } \\
\text { memori }\end{array}$ \\
\hline
\end{tabular}

\begin{tabular}{|c|c|c|}
\hline Kategori & Risiko & Rekomendasi \\
\hline & $\begin{array}{ll}\text { penyimpanan } \\
\text { dengan } & \\
\text { menyimpan } & \text { data } \\
\text { laporan yang } \\
\text { sudah } \quad \text { tidak } \\
\text { digunakan } & \\
\end{array}$ & $\begin{array}{l}\text { peyimpanan } \\
\text { sehingga dapat } \\
\text { menghemat biaya } \\
\text { untuk perangkat } \\
\text { penyimpanan } \\
\text { memori }\end{array}$ \\
\hline $\begin{array}{l}\text { Pengendalia } \\
\mathrm{n} \text { basis data }\end{array}$ & $\begin{array}{l}\text { Tugas database } \\
\text { administrator } \\
\text { dan data } \\
\text { administrator } \\
\text { belum terpisah, } \\
\text { hal ini beresiko } \\
\text { bocornya data } \\
\text { atau informasi } \\
\text { karena data } \\
\text { manajemen user } \\
\text { ditangani dan } \\
\text { diketahui oleh } \\
\text { database } \\
\text { administrator. }\end{array}$ & $\begin{array}{l}\text { Membagi } \\
\text { beberapa divisi } \\
\text { yang bertugas } \\
\text { untuk menangani } \\
\text { sistem database } \\
\text { dan kebutuhan } \\
\text { manajemen user }\end{array}$ \\
\hline $\begin{array}{l}\text { Pengendalia } \\
\text { n } \\
\text { komunikasi } \\
\text { aplikasi }\end{array}$ & $\begin{array}{l}\text { Tidak adanya } \\
\text { error detection } \\
\text { jaringan pada } \\
\text { saat pengiriman } \\
\text { data, hal ini } \\
\text { dapat } \\
\text { mempengaruhi } \\
\text { keamanan data } \\
\text { pada saat } \\
\text { pengiriman data. } \\
\text { Terdapat celah } \\
\text { yang dapat } \\
\text { digunakan untuk } \\
\text { meretas, } \\
\text { membaca, atau } \\
\text { menduplikasi } \\
\text { data oleh orang } \\
\text { yang tidak } \\
\text { bertanggung } \\
\text { jawab }\end{array}$ & $\begin{array}{l}\text { Sebaiknya } \\
\text { jaringan } \\
\text { menggunakan } \\
\text { layer diatas tiga } \\
\text { untuk mendeteksi } \\
\text { error atau } \\
\text { merahasiakan } \\
\text { data mengunakan } \\
\text { mengik enkripsi } \\
\text { teknik tata yang telah } \\
\text { dimodifikasi }\end{array}$ \\
\hline
\end{tabular}

\section{KESIMPULAN DAN SARAN}

a. Kesimpulan

Kesimpulan dai penelitian ini adalah hasil evaluasi pengendalian aplikasi menggunakan framework COSO pada sistem informasi manajemen keuangan di dinas komunikasi, informatika dan persandian kabupaten Banyuwangi menunjukkan bahwa sistem informasi yang telah diterapkan pada instansi tersebut mendapatkan nilai 84.5 dengan kriteria penilaian baik. Pengendalian aplikasi dapat digunakan untuk memperbaiki kelemahan sistem informasi yang telah dikembangkan, menjaga keamanan data dan informasi, meminimal risiko sistem informasi yang dapat merugikan pihak terkait serta menjaga keberlangsungan sistem informasi. 


\section{b. Saran}

Saran untuk pengembangan atau lanjutan penelitian berikutnya adalah agar dapat dikembangkan suatu sistem yang bisa dipergunakan untuk kegiatan evaluasi pengendalian aplikasi. Dapat digabungkan dengan framework atau metode lain untuk meningkatkan keamanan informasi maupun performa sistem informasi.

\section{REFERENSI}

Sanyoto, G. (2007). Audit sistem informasi + pendekatan CobIT. Edisi Revisi, Penerbit: Mitra Wacana Media, Jakarta.

Paulina, G. (2014). Audit Tata Kelola Teknologi Informasi Berbasis Risiko dengan Menggunakan Framework Risk IT dan COBIT 4.1. Audit Tata Kelola Teknologi Informasi Berbasis Risiko dengan Menggunakan Framework Risk IT dan COBIT 4.1.

Fajar, I., \& Rusmana, O. (2018). EVALUASI PENERAPAN SISTEM PENGENDALIAN INTERNAL BRI DENGAN COSO FRAMEWORK. Jurnal Ekonomi Bisnis dan Akuntansi (JEBA), 20(4).

Manurung, E. T. (2014). STUDI ATAS IMPLEMENTASI SISTEM INFORMASI BERBASIS KOMPUTER UNTUK MENGENDALIKAN KEGIATAN PEMBELIAN DI PERUSAHAAN TEKSTIL HM DI BANDUNG. Bina Ekonomi, 18(1).

Papilaya, F. S., \& Manuputty, A. D. (2017). Evaluasi Pengendalian Aplikasi pada Sistem Informasi Keuangan dan Akuntansi Satya Wacana (SIKASA). Jurnal Sistem Informasi Indonesia, 2(1).

Rivai, A. (2012). Analisis Dan Evaluasi Pengendalian Intern Dalam Sistem Informasi Akuntansi Terkomputerisasi Pada PT Transavia Otomasi Pratama.

Aviana, S., \& Mega, P. (2012). Penerapan pengendalian internal dalam sistem informasi akuntansi berbasis komputer. Jurnal Ilmiah Mahasiswa Akuntansi, 1(4), 65-70.

Krismiaji, E., 2002, Sistem Informasi Akuntansi, Yogyakarta: Unit Penerbit dan Percetakan AMP YKPN.

Hidayat, W. (2017). Kementrian Komunikasi dan Informatika Republik Indonesia. Diakses pada, 10 Juni, 2019, dari https://kominfo.go.id/content/detail/4286/ pengguna-internet-indonesia-nomorenam-dunia/0/sorotan_media. 